\title{
Urban cooling primary energy reduction potential: system losses caused by microclimates
}

\author{
Forrest Meggers $^{\mathrm{a}, \mathrm{b}}$, Gideon Aschwanden ${ }^{\mathrm{c}}$, Eric Teitelbaum ${ }^{\mathrm{d}}$, Hongshan Guo ${ }^{\mathrm{a}}$, Laura \\ Salazar $^{\mathrm{a}}$, Marcel Bruelisauer ${ }^{\mathrm{e}}$ \\ ${ }^{a}$ Princeton University, School of Architecture, Princeton, NJ, 08544, USA \\ ${ }^{b}$ Princeton University, Andlinger Center for Energy and the Environment, USA \\ ${ }^{c}$ The University of Melbourne, Melbourne School of Design, Melbourne, Australia \\ ${ }^{d}$ Princeton University, Department of Civil and Environmental Engineering, USA \\ ${ }^{e}$ Future Cities Laboratory, Singapore-ETH Centre, Department of Architecture, ETH Zürich, Zürich, Switzerland
}

\begin{abstract}
Temperatures in cities are amplified through the urban heat island effect by anthropogenic emissions into microclimates. The trapping of solar energy in urban canyons plays the most significant role. Our analysis, however, considers how urban air conditioning systems influence their local microclimate. Using models and simple observations we demonstrate how the heat rejected from these machines creates a direct feedback on the machine performance. . Thermodynamically, the temperature of the environment directly controls the efficiency of the common refrigeration cycle found in air conditioning systems via the second law. A city, with its complex topography of urban canyons and skyscrapers, produces small microclimates with varying temperatures. This project investigates three urban settings that create microclimates that are detrimental for the efficiency of cooling in New York. First, the overall urban heat island effect, second the effect of roof temperature on rooftop package air conditioning units, and third the impact of local heat emission from agglomerations of window air conditioners. The efficiency loss is investigated by considering the range of temperature changes that can be observed in the surrounding environment of air conditioning systems, and determining the subsequent impact on the Coefficient of Performance (COP). Our COP analyses indicate a range of potential energy increases of around $7 \%$ to $47 \%$ due to increases in environmental temperature around air conditioners. An analysis of the building stock of New York City showed that the electrical energy demand is potentially increased by these effects by nearly $10,000 \mathrm{TJ}$ combined, which is more than $10 \%$ of the total cooling demand for the city.
\end{abstract}

Keywords: COP, energy efficiency, cooling, urban, air conditioning

(C) 2016. This manuscript version is made available under the Elsevier user license http://www.elsevier.com/open-access/userlicense/1.0/ 


\section{Introduction}

This paper investigates the impact of high-density urban situations on the energy efficiency of air conditioning units whose performance is sensitive to the surrounding environmental temperatures. The focus lies on three factors that change the environment in which the heat exchanger of the air conditioner is working. The first is the Urban Heat Island (UHI) effect, which is the overall increase in temperature due urban form, material, and emissions that raises the local temperature for all units. The second is the surface material in the immediate surrounding of the units raising the temperature locally. The last factor is the geometrical distribution of units where the dissipated heat raises the temperature of units in the vicinity or themselves as in the densely arranged and vertically oriented units shown in the photos in Figure 1. Even though these three factors are complementary this paper investigates the impact of them individually. We present the background on these factors on which we build our assumptions and models, then we describe the methods we used to estimate the impact on thermodynamic performance, we layout the results for each scenario, and then we discuss the results including their implications and uncertainties.



Figure 1: Image illustrating the stacking of heat exchange units in the urban canyons of New York City (left), and attached to buildings in Singapore (right) 


\section{Background}

\subsection{Urban Heat Island (UHI)}

The urban heat island effect has been identified as, "high surface and thermal structure heterogeneity, complex localized flow patterns inside street canyons radiative trapping, artificial materials, anthropogenic heat releases, as well as finite domains for heat conduction, instead of the semi-infinite sub-surface domain that can be assumed over natural terrain" [1]. Causes that have been identified include excessive anthropogenic heat, storage of solar radiation in large thermal masses with insufficient circulation, reducing the ability for infrared radiation to escape the atmosphere, causing nighttime temperatures in urban areas to rise significantly above surrounding conditions [2]. Since the UHI effect produces a temperature differential during the night hours, the an impact on air conditioning performance relative to nominal conditions would happen at night and affected roughly $1 / 3$ of the time in summer.

The absorbed radiation is stored in the attached materials and dissipated through radiation [3]. Depending on the thermal storage capability of the surrounding materials, the dissipation of the absorbed energy occurs with a delay over hours and leads to the known fact of increased temperature in cities overnight [2].

The adverse impact of urban heat islands has been extensively studied and identified to increase energy consumption and peak electricity demand during cooling seasons as well as decreasing the Coefficient of Performance (COP) by as much as $25 \%$ [4], eventually deteriorating the outdoor thermal comfort [5]. Strategies for maintaining the urban thermal balance have been developed including increasing the albedo of the urban environment, expanding the urban green spaces and utilizing natural heat sinks within or near the vicinity of the urban area. Such mitigation techniques have been demonstrated to be effective and beneficial for large-scale applications [6].

Of the aforementioned mitigation techniques, some are not as usable as the others: The available free ground in cities, for example, isn't always as abundant as the designers would like to believe, and could render the implementation of large-scale mitigation methods ineffective. The mitigation methods that are based on roofs, on the other hand, are highly preferable due to their flexibility and ease of implementation due to the costs, thereby 
cultivating strategies that aimed at increasing the albedo effect of cool/reflective roofs [7].

Previous studies have also considered the impact of environmental temperatures on air conditioner performance [8] [9]. Allegrini et al. looked at the impact of urban form and UHI on building performance using simulation and analysis of convective and radiant heat exchanges caused by urban conditions, but it did not consider specifically the direct impacts and feedback between temperature and system performance as these aspects were built into the simulation tool [8]. Gracik et al used computational fluid dynamics to simulate temperatures and did study the influence on the performance of air conditioners, but the analysis was limited to simulation of simplified large scale building forms to facilitate the complex fluid dynamics analysis [9]. We are interested in three specific aspects of the microclimate in the context of a case study of New York City.

\subsection{Surface Materials}

The local temperature is impacted by the material relationship to its immediate surroundings, in particular the material absorption and storage capacity. It affects local temperatures and impacts equipment such as rooftop package air conditioners. Prado explains how the radiative exchange of the solar radiation depends strongly on the material and can range from $10 \%$ to $73 \%$ [10]. The orientation also plays a critical role in the radiant heat transfer and the retransmission into the local microclimate by convection and emission. Even for high albedo surfaces, the more times short wave radiation bounces, the more likely it is to be absorbed instead of reflected. The orientation of surfaces toward the sun and the geometry that generates these reflections are critical in understanding the heat stored and exchanged within local microclimate [2].

Choosing appropriate surface materials improves energy efficiency by regaining the losses in performance caused by high local temperatures around the split type air conditioner condensers and potentially achieves energy savings. To be more specific, we consider the material causing change in the environmental temperature for the rooftop package units that leads to a change in their performance [11].

Our three major areas of interest in this direction are the influence of the reflectivity, thermal capacity and the capabilities of evaporative cooling. According to the research of [12] between the unpainted cement surface and 
different colored paints, the cool white paint could reduce the heat flux up to $37 \%$ with a solar reflectance of 0.78 [12]. As with thermal capacity of significant thermal masses, a study by Jim in 2014 revealed that with a higher level of building thermal insulation in contrast to unshielded building blocks could not only cut heat ingress, but could also suppress the cooling load by $33.15 \%$ [13]. A simplified estimation can therefore be made as to the impact of choosing appropriate envelope materials has on the performance of air conditioning units.

These types of effects lead to the introduction of the term SUHI (Surface Urban Heat Island) [11]. These are the changes caused directly at material surfaces, whereas the UHI is a general heating of the urban atmosphere. For our case, the very small microclimate around the air conditioner is more closely linked to the surface conditions so we are also interested in surface temperature impacts. Observations in Minneapolis quantified the difference between the surface temperature in the urban areas and the surrounding rural areas to $24{ }^{\circ} \mathrm{C}[11]$. The work of Bourbia showed surface temperature rise of up to $25^{\circ} \mathrm{C}$ in the urban canyon of a desert setting above the surfaces, with a combination of UHI and surface effects in an extremely hot and sunny condition [14]. Wong et al. measured temperatures of hard roof surfaces and vegetated roof surfaces and found that hard surfaces can have temperatures $30{ }^{\circ} \mathrm{C}$ higher than vegetated surfaces that are near ambient conditions, and Wong et al. also found the air $0.3 \mathrm{~m}$ above typical hard surfaces to be $6^{\circ} \mathrm{C}$ higher than conditions above vegetated surfaces at $1 \mathrm{~m}$ [15]. The Gratz building in New York City had its roof top temperature extensively monitored in a study evaluating vegetated “green” roof performance by NYSERDA (New York State Energy Resource and Development Authority) for the Pratt Center for Community Development. They found that typical temperatures above typical flat roofs climb above $70{ }^{\circ} \mathrm{C}$ in the summer months. In this case the air temperature sensors were shielded in such a way that temperature increases caused by radiant heat transfer from the hot roof to the surrounding were not detected [16].

\subsection{Stack Effect}

A primary culprit in the increased energy demand due to increased temperatures in the microclimate around building systems is also the stacking of condensing units for window air conditioners leading to decreased COPs. As was identified by previous studies [17] the stacking of the condensing units could lead to localized urban heat island 
effect resulting in the increase of local temperature at 2 to $4{ }^{\circ} \mathrm{C}$ at 40 stories. More recent research has experimentally found that such a setup decreases performance of air conditioning units in a 25 storey building, creating a $40 \%$ decline in the COP at the 25 th floor due to the 'stuck and stack' effect identified by Bruelisauer et al. [18]. They were able to show that the local microclimate generated by air conditioner heat rejection differs from the surrounding environment by up to $13{ }^{\circ} \mathrm{C}$ from the stacking of units, and in the case of a confined spaces designed to hide unsightly mechanical units, an additional $7^{\circ} \mathrm{C}$ are is contributed by the effect of the unit being "stuck." This work indicates that local microclimatic variances have an even higher effect than the overall urban heat island. Recent work analyzing the temperature distribution in low-rise neighborhoods has shown that a stack effect of $2-3$ ${ }^{\circ} \mathrm{C}$ is measurable already on 3-storey buildings, caused by heat trapped in street canyons [19].

The changes to the outside temperature depend both on the amount of energy dissipated into the environment and the size of the heat sink that absorbs the energy. In most cases the assumption is that the heat sink is the surrounding air that constantly moves and can carry the emitted energy away. This is not the case in the urban environment where distances between buildings are limited, heat exchangers are hidden behind blinds, and the urban canyon creates eddies that accumulate the dissipated heat. In all of these cases there are impacts on efficiency.

\section{Method}

We have developed a method to extract from a broad set of data on New York City energy consumption for air conditioning to understand how it is impacted directly by the anthropogenic heat emissions of the city. Typically building energy efficiency is addressed through simple interventions to aspects like insulation and glazing on the building shell. We examine the urban impacts from increased temperatures directly on the energy consumption of the air conditioning systems supplying cooling to buildings. In this case the cooling demand is fixed, and the thermodynamic relationship between temperature and air conditioner performance is leveraged independent of the cooling demand supplied. We therefore can demonstrate opportunities to reduce primary energy demand and associated emissions from thermodynamic relationships of air conditioning to microclimatic conditions in the urban environment, in this case for New York City. In the larger urban scale case of UHI, air conditioner emissions 
themselves play a role in adding heat to the urban canyon. In the other two of the cases the heat rejection emissions of the air conditioners themselves play a major role in the increased temperature in the microclimate around the units.

To build on previous simulation work $[8,9]$, we aim to use an urban case study with real data from New York City to approximate an impact from three scenarios where the local heat emissions at the local microclimate around air conditioning units are considered. This will allow us to quantify an impact on urban scale energy consumption for a large case study city that considers highly distributed small-scale impacts occurring at the interface between air conditioners and the urban microclimate.

The performance metric used to evaluate the energy efficiency for building cooling systems is the 'coefficient of performance' (COP). Its dependence on the temperature at which heat is rejected from the system creates the feedback from the microclimatic condition on the system performance. For thermodynamic systems, such as an air conditioning unit, efficiency is inextricably linked to temperature. Theoretical Carnot efficiencies are simple to calculate, however the actual Carnot efficiency depends on the hot and cold temperatures within the system and the associated microclimate. We have developed an analysis that deals with the conditions associated with each microclimate. [7].

\subsection{COP Calculation and Performance}

The COP was calculated using the ideal Carnot efficiency in Equation 1, which directly links the performance of an air conditioner or heat pump to the temperature difference ( $\left.T_{\text {hot }}-T_{\text {cold }}\right)$ across which heat is removed or provided. Typical COP values for air conditioner units range from 3 to 5 units of cooling provided per unit electricity used. This number reflects the machine COP, efficiency, and temperature increase across the heat exchanger. In reality, the machine COP independent of temperature increases associated with geometries would be higher. The formula demonstrates that performance decreases with an increase in the temperature difference as the difference is in the denominator below the absolute cooling temperature. The Carnot COP given in Equation 1 depends on exergetic efficiency, $g$, because real machines have additional internal losses that make them operate at a fraction of their ideal 
efficiency. Typical machines range from 0.4 to 0.6 [18]. We chose a value of 0.5 as average for normal machines when calculating COP values.

$$
C O P_{\text {cooling }}=g \times \frac{T_{\text {cold }}}{T_{\text {hot }}-T_{\text {cold }}}
$$

The cooling temperature, $T_{\text {cold }}$, was fixed assuming standard indoor cooling conditions, and based on previous work measuring evaporator coil temperatures a temperature of $7^{\circ} \mathrm{C}$ was chosen [20]. In order to create a baseline heat rejection temperature into the outdoor environment, $T_{\text {hot }}$, we used the TMY3 datafile for John F. Kennedy International airport in New York City [21] which provides an average dry bulb temperature of $21.5^{\circ} \mathrm{C}$ for air conditioning months of May-August. Based on data measured in previous work across the heat exchanger of the condenser of the air conditioner there is a $9{ }^{\circ} \mathrm{C}$ temperature increase [18]. For this reason, $T_{\text {hot }}$ is set to $30{ }^{\circ} \mathrm{C}$ as the representative value for an ideal air conditioner heat rejection temperature.

Since the COP tells the amount of heat delivered per unit electricity in this scenario, we can establish a percent increase or decrease in the COP from a baseline value, and multiply this change by the electricity consumed to arrive at a final value. Equation 2 is used to calculate the change in electricity consumption based on a specific microclimate, $\Delta E_{\text {microclimate }}$, by multiplying the electricity consumption to provide cooling within the microclimate, $E_{\text {cooling }}$ with change in COP ratios. In this case the machine efficiency cancels out so that assumption can be neglected for the comparative study as our analysis is on existing machines whose efficiencies will be constant in different temperature scenarios.

$$
\Delta E_{\text {microclimate }}=\frac{C O P_{\text {ideal }}-C O P_{\text {real }}}{C O P_{\text {ideal }}} \times E_{\text {cooling }}
$$

In buildings, there are a multitude of heat gains, namely solar, internal loads, heat transmission, etc. This study assumes none of these are changing. Instead, we are examining solely the systematic change in system COP, because this is the metric that determines the actual primary energy needed to remove heat from a building, regardless of solar gains, insulation, etc. 


\subsection{UHI Calculation}

Since the UHI effect is most prominent during the night hours, the air conditioner heat exchange units are estimated to be affected $1 / 3$ of the time or 8 hours of the day [2]. In order to obtain the energy demand of all air conditioners in NYC, economic data from NYCEDC (New York City Economic Development Corp) was used that provided an the overall energy use in NYC of $1 \mathrm{EJ}$, and stated that $9 \%$ was for cooling [22], which was based building energy benchmarking analysis of LL84 benchmarking data done by Kontokosta for the office of the Mayor [23]. This results in $90 \mathrm{PJ}$ as the total cooling electricity demand for New York City.

Material thermal storage and the resulting dissipation lag are a major contributor of night temperature rises as observed in Tokyo by $8{ }^{\circ} \mathrm{C}$, in Seoul by $4.5^{\circ} \mathrm{C}$, Bangkok by $5^{\circ} \mathrm{C}$ [24]. New York City experiences a UHI of around $4^{\circ} \mathrm{C}$ [25]. In order to validate temperatures at the interfaces of buildings, we did an extensive survey of New York City using a thermal camera to measure surface temperatures in the small urban spaces in the city, while also recording air temperature data.

In order to calculate the New York City savings the nominal UHI of $4{ }^{\circ} \mathrm{C}$ was used for the temperature increase. Equation 2 is used to calculate this increase, with $E_{\text {cooling }}$ set to $90 \mathrm{PJ}$, and multiplying by $1 / 3$ to account for the 8 hours per day when the effect is present.

\subsection{Surface effect}

The calculation of rooftop packaged air conditioning units' contribution to electricity consumption was based on the fraction of buildings that are commercial buildings in the city, the percentage of commercial buildings that are cooled, the percent of cooled commercial buildings that use rooftop package air conditioning units, the average square footage of office buildings, and the energy consumption per square foot of package units. New York City property tax data gave us the number of commercial buildings at 6485 [26]. Data for office buildings in the northeast provided by CBECS were used to determine that $41.1 \%$ of office buildings in the northeast use packaged air conditioners, giving us a total of 2668 office buildings for calculation, and additionally, data for Mid-Atlantic office building square footage from CBECS were used to arrive at an average of $1,858 \mathrm{~m}^{2}\left(20,000 \mathrm{ft}^{2}\right)$ per office building 
[27]. This was used as a lower bound, and data for Manhattan office space of $9,290 \mathrm{~m}^{2}\left(100,000 \mathrm{ft}^{2}\right)$ per office building were used as an upper bound in calculations. A value of $232.5 \mathrm{MJ} \mathrm{m}^{-2}$ was used as the electricity consumption to calculate the overall electricity consumption of all packaged units in NYC [28]. The electricity consumption is impacted by the environmental temperature, which influences the COP. We estimated the influence on COP from the work of Bourbia, which showed surface temperature rise of up to $25^{\circ} \mathrm{C}$ [14]. However, Wong et al. demonstrated that this surface temperature may not significantly impact the air temperature even $30 \mathrm{~cm}$ above the surface [15]. For this reason, we examined a temperature increase between 2 to $6{ }^{\circ} \mathrm{C}$. Again, equation 2 is used to calculate the increase in electricity consumption, $\Delta E_{\text {Roof top }}$.

Again the thermal imaging survey was used to evaluate the local temperature increases that have been assumed. The images do not provide a direct link between surface and air temperature, but support the studies that demonstrated very high surface temperatures. For the large survey, roofs were imaged from a distance and were unable to measure air temperature directly. Still, the air would be highly unstable in the vicinity of the exhaust of a condenser unit, and future work should aim to refine this characterization through modeling or more long-term measurement.

\subsection{Stack effect}

To estimate the scale of stack effect influences to overall consumption, the individual energy consumption of window air conditioning units and total number of these units had to be determined. With these numbers, the annual electricity consumption of all window air conditioning units in NYC could be extrapolated. Data was extracted from Urban Green Council who estimates 4 million window units in NYC with 286 operating hours per year [29]. With an average of $3.5 \mathrm{~kW}$ electricity consumption based on DOE RECS [30] combined with 286 hours operating per year, a yearly electricity consumption of $7196 \mathrm{MJ}$ is determined for each unit. Although we observed this temperature increase to generally be the case, not all units experience higher temperatures. Our thermal imaging survey showed that about $75 \%$ of units are either installed above other units' heat emissions or in confined spaces under awnings or other flow restricting structures. We therefore assumed that $25 \%$ are not affected, leaving 3 
million units affected. The thermal camera was deployed to observe local window air conditioners and the impacts they have on the microclimate around themselves, and also on their neighbors. We examined the COP-dependence on temperatures ranging from 8 to $20^{\circ} \mathrm{C}$, which takes into account a baseline of stack-dependent temperature increases, and at the high end considers additional potential heating caused by stuck or trapped air around units [18].

\section{Results}

Overall, we found there is a wide variation in the potential temperature changes that can occur in the urban microclimates. The methods make it clear that there is a high variability in the potential impacts and temperatures of the systems. Figure 2 is a stitched together image of a section of New York City. In it a range of temperatures is shown, and in this case the important aspect is how the thermal variation presents itself across scales, materials and spaces. It demonstrates how temperatures that would impact system performance can emerge in a wide range of settings out of the fundamentally heterogeneous urban fabric.

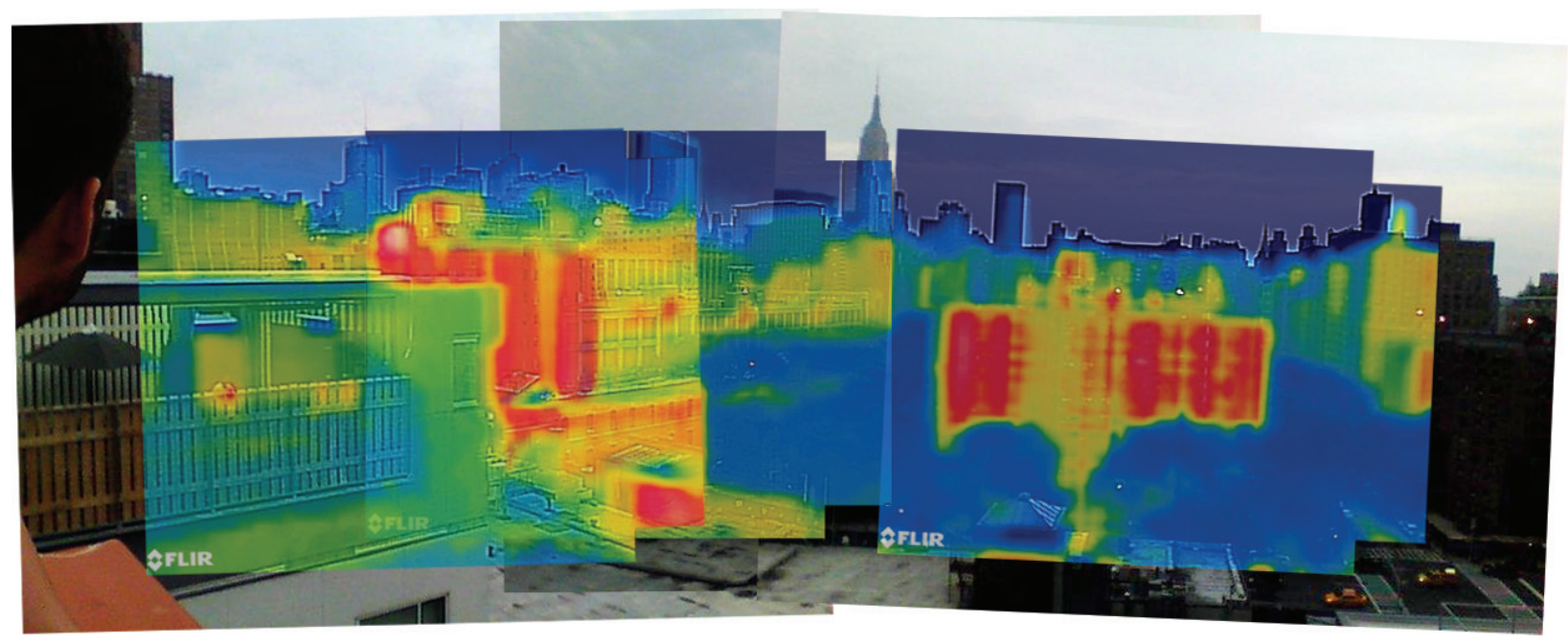

Figure 2 Stitched collage of the variety of temperatures displayed through thermal imaging across various elements of the urban fabric, illustrating the challenge of understanding the impacts of these warmer elements and spaces on system performance and energy demand

We have successfully filtered down three specific scenarios where we can leverage data and observation to make calculations on how these varied temperatures can have a generalized effect based on systematic design decisions that take place in the geometry, orientation and location of cooling systems in buildings. We compiled the 
temperatures extracted from our background research and used the basic thermodynamic methods described to first create an overview of the impact on COP performance, and subsequently the actual impact on primary energy demand for cooling of New York City.

\subsection{COP Calculation}

Figure 3 shows the impact on COP from our three scenarios. The baseline of $30{ }^{\circ} \mathrm{C}$ to the left shows a COP of 6 , higher than typically found in units, but we are assuming most units are designed and operated in anticipation of these higher temperatures, decreasing nominal COP found in the market. We are using a machine efficiency of $50 \%$, which would also be on the high end for many inexpensive units. Additionally, the machines are designed to operate for given design loads and our analysis is for an average load to account for the potential across the summer heating season, so typical COP ratings are for heat rejection at higher temperatures.

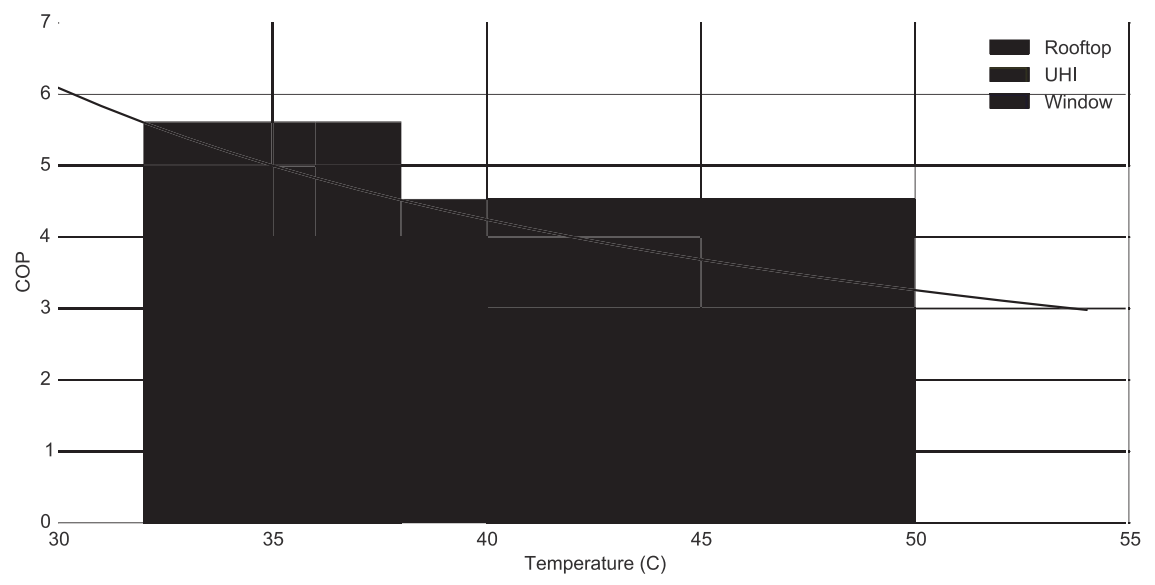

Figure 3: Performance of a heat pump as a function of the outside temperature variance. There is an overlap between the UHI and Rooftop domains.

Taking into account the various UHI temperature impacts reviewed in the background and defined in the methods, a temperature from 2 to $8{ }^{\circ} \mathrm{C}$ is presented for UHI. The increased temperatures caused at building surfaces were based on temperatures from the study by Wong that showed local air temperature increases of 2 to $6{ }^{\circ} \mathrm{C}[15]$. The window air conditioning increase ranges from 8 to $20{ }^{\circ} \mathrm{C}$. The COP drops for a $50 \%$ machine efficiency from a 
value of 6 units of cooling per unit primary electricity input to almost between 4.5 and 5 for the UHI and rooftop effects and down to 3.2 for the window air conditioners. Table 1 summarizes the results of the calculations.

Table 1: Summary of COP and energy savings

\begin{tabular}{|c|c|c|c|c|c|c|c|c|c|c|}
\hline Case & UHI & & & Roof & & & & Wind & & \\
\hline & & & & 1,858 & & 9,29 & & & (stuck & fect) \\
\hline Temp Increase $\left({ }^{\circ} \mathrm{C}\right.$ & & 4 (NYC) & 8 & 2 & 6 & 2 & 6 & 8 & 12 & 20 \\
\hline $\mathrm{COP}$ & 5.6 & 5.2 & 4.5 & 5.6 & 4.8 & 5.6 & 4.8 & 3.6 & 3.2 & 2.6 \\
\hline Elec. $\%$ & 8 & 15 & 26 & 8 & 21 & 4 & 21 & 26 & 34 & 47 \\
\hline Elec. Increase (TJ) & 2500 & 4600 & 8100 & 46 & 120 & 230 & 370 & 3700 & 4900 & 6700 \\
\hline Cooling elec. $\%$ & 2.6 & 4.9 & 8.5 & 0.05 & 0.1 & 0.2 & 0.4 & 3.9 & 5.2 & 7.1 \\
\hline
\end{tabular}

\subsection{UHI Overall Impact}

Using the estimated UHI temperature increase for NYC that occurs during the nighttime or roughly $1 / 3$ of the hours of the day, the reduced the COP results in an increased primary energy demand for cooling of $4600 \mathrm{TJ}$ by UHI at night. The decrease in the COP of the air conditioning units for the ranges between 2 and $8{ }^{\circ} \mathrm{C}$ from the $\mathrm{UHI}$ results in an increase in cooling electricity consumption of $8-26 \%$ for affected machinery. In a larger perspective, the $4{ }^{\circ} \mathrm{C}$ temperature increase from UHI adds to the electricity balance sheet by $4600 \mathrm{TJ}-$ almost $1 \%$ of the total energy budget of the city of $1 \mathrm{EJ}$. The entire domain of a 2 to $8{ }^{\circ} \mathrm{C}$ increase adds between $3 \%$ and $8 \%$, respectively, to the overall cooling electricity budget.

The results of the thermal imaging survey, which consisted of hundreds of images, confirmed an overall temperature increase on the order of 2 to $8^{\circ} \mathrm{C}$ across the surfaces of the buildings where the cooling systems are installed. This is illustrated in the image in Figure 4. 


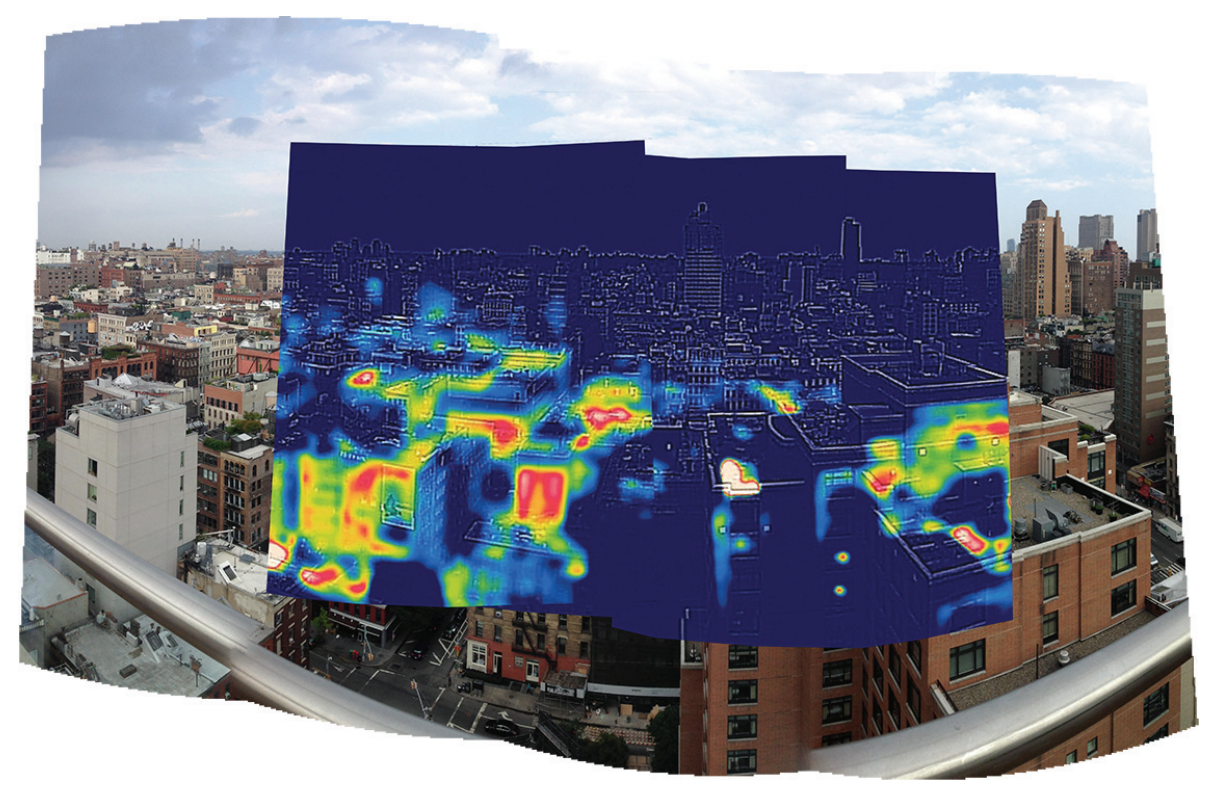

Figure 4 Thermal image of the overall temperature increase in the urban fabric

\subsection{UHI Rooftop / Materials}

Based on local temperature increases on roofs of 2 to $4{ }^{\circ} \mathrm{C}$, an $8 \%-21 \%$ increase in electricity demand for rooftop package unit operation was determined. For the lower bound of $1,858 \mathrm{~m}^{2}\left(20,000 \mathrm{ft}^{2}\right)$ per office building, this translates to a $50 \mathrm{TJ}$ to $120 \mathrm{TJ}$ increase in electricity consumption for the 2 to $6{ }^{\circ} \mathrm{C}$ range. For the higher bound of $9,290 \mathrm{~m}^{2}\left(100,000 \mathrm{ft}^{2}\right)$ per office building, this becomes a $230 \mathrm{TJ}$ to $370 \mathrm{TJ}$ increase in electricity demand for the same 2 to $6{ }^{\circ} \mathrm{C}$ range. These numbers are small, representing between $0.1 \%(50 \mathrm{TJ})$ and $0.4 \%(370 \mathrm{TJ})$ of the overall cooling electricity budget.

The thermal imaging of building surfaces in the sun confirmed the dramatic temperature rises, as is shown in the Figure 5. The impact on air temperatures and the interface between the units placed at these surfaces is not as extreme as reported in the background and methods. 


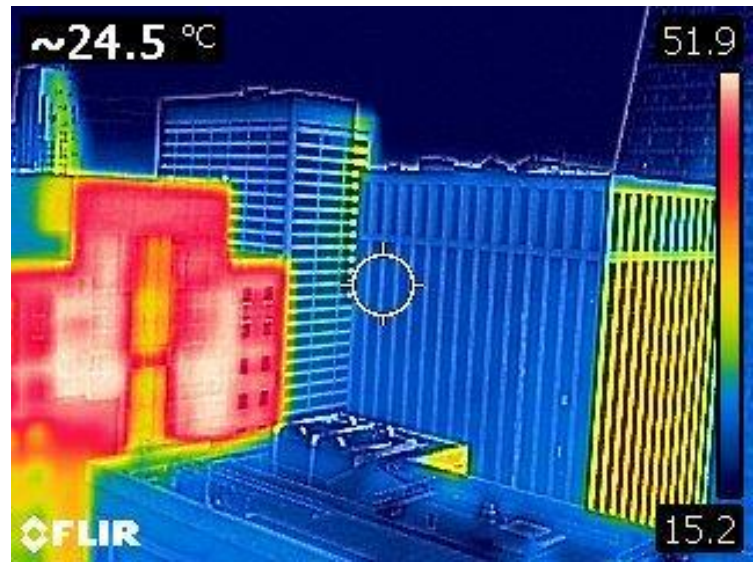

Figure 5 Temperature increase on the surface of a building in the sun

\subsection{Stack Effect \& Window Aircon}

An increase between 8 to $20^{\circ} \mathrm{C}$ rise in the ambient temperature leads to an increase of electricity consumption between $26 \%$ to $47 \%$. The added electricity consumption due to the stack and stuck effect of air circulation around window units is 3700 to 6700 TJ. These values are $4-7 \%$ of the total cooling demand of New York City. The thermal imaging study showed many cases of window unit systems having very high temperatures, indicating inefficient performance as shown in Figure 6. 


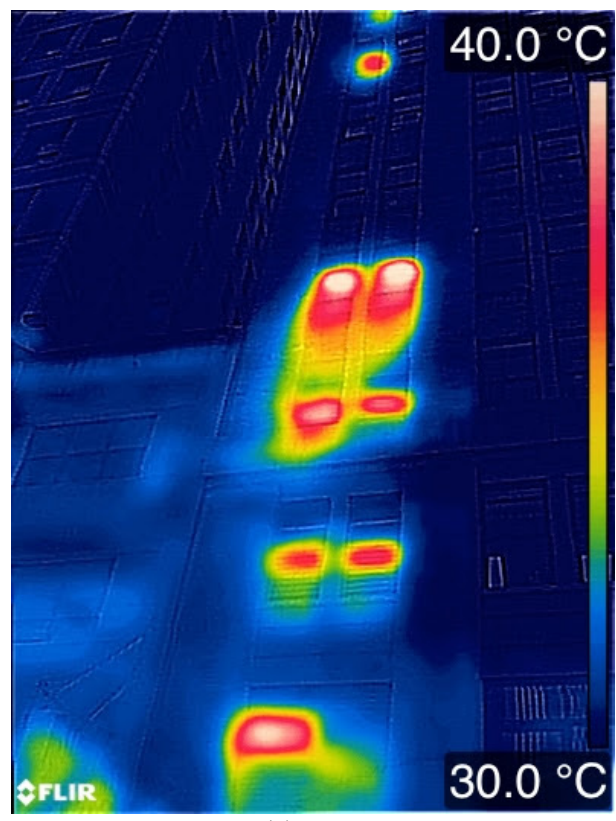

(a)

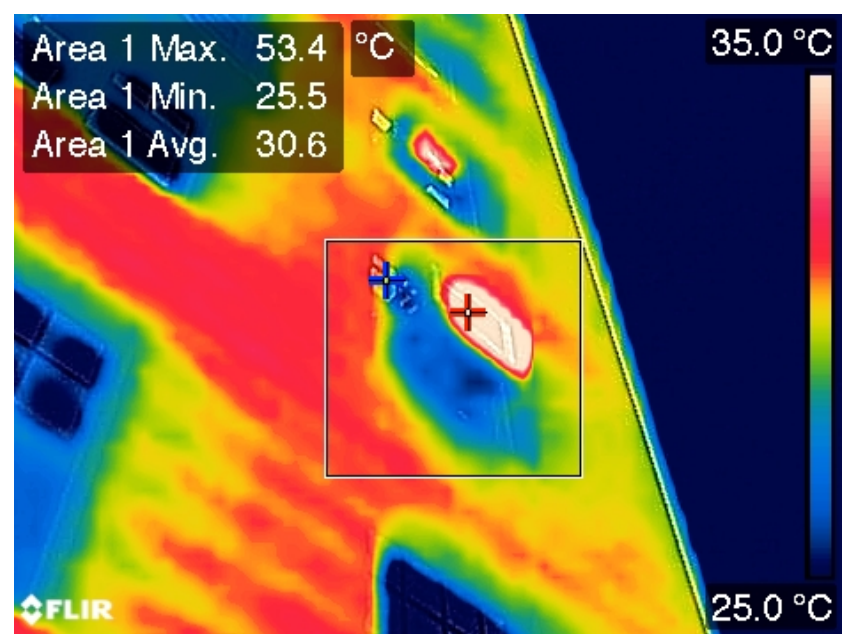

(b)

Figure 6 Window air-conditioners being impacted by local heating of the microclimate from adjacent units and surfaces, a) showing the heat rising between units by proxy through increased surface temperature between them, b) High absolute local temperature at the unit surfaces have direct local impacts on performance.

\section{Discussion}

This study investigated the UHI, surface material, and the stack effect individually without investigating the interdependency between them. The UHI has the most fundamental effect by increasing the overall ambient temperature. This has an effect on all air conditioning units within the city. With changes in rooftop surface material not only the local temperature for the packaged air conditioning units is affected but also the overall albedo and energy storage capacity of the city. A reduction in the absorption and storage capacity of the city will have a diminishing effect on the evening UHI. The overall aspects of the anthropogenic heat production and its effect on the UHI and local thermal conditions are not taken into account in this project. A special case of this are "nanoclimates' where air conditioning units are placed in a confined space with limited exchange to the environment that heat up and reduce the COP over time.

The cumulative effect of a reduction in any of the three factors is a reduction in energy consumption and a reduction of impact on the overall temperature of the city. This in turn will have an impact on the COP of all air 
conditioning units, allowing the air conditioning units to consume less electricity, reducing the anthropogenic heat production and in turn amplify further the reduction in consumption.

The results are based on an initial analysis using assumptions built on a substantial review of published data, research and information. The review focused on the three microclimatic conditions we describe, which impact local air conditioning performance. In many cases the assumptions generalize and extrapolate information from other cases into the New York City condition, so future work will aim to increase the reliability, and to also collect data directly to substantiate and improve these assumptions. In this paper we present our results based on ranges of values that fit our assumptions, which provide a range of impacts that although not specific, still indicate significant feedback from microclimates on cooling energy demand in the city. We believe the results shed important light on the complex interactions between energy infrastructure and urban climate.

Research has shown the importance of considering the complex physical interactions across scales in the urban climate [31], and there we are considering various ways to mitigate the impacts we have calculated. Latent energy is one obvious area to consider because adding any moisture to any surface or system significantly alters the heat capacity as evaporative cooling can have powerful influence [32]. The relatively small temperature increase observed from the UHI and stack effect could be matched adequately with latent heat rejection methods. Teitelbaum et al. present a method for compartmentalizing a latent heat and mass exchanger on the facade of a building to reduce the UHI [33], and Bruelisauer et al. investigate methods for using a heat bus system to transfer heat to a central latent rejection system [19], [20], [34]. This method can increase COP of air conditioning units from about 3 to almost 6, depending on demand [20]. This result would translate favorably to NYC, as the climate is less humid.

Another temperature effect that could be considered is the impact of plant and water systems on the energy exchange at surfaces and in the air around systems. The evapotranspiration of plants, their lower radiant surface temperatures, and the storage and distribution of latent energy in water in urban ecosystems could play a role to counteract the effects we have generalized and quantified here. Jenerette has demonstrated the value of temperature lowering of ecosystems as an urban service [35], and we could employ this type of analysis to consider applied mediation techniques using natural systems in proximity to traditional HVAC systems. 
Although we suspected the impact from the rooftop temperatures would be high due to analysis discussed in the methods and initial conference paper [36], further review of previous research has shown that the impact on air temperatures above hot surfaces is less significant. Therefore, we chose a relatively low temperature effect. Nevertheless, we suspect the surfaces of the equipment may be heating up as well, shifting the temperature range of the COP dependence. There is no research considering this impact yet and is a potential area of future work..

This study is an important first approximation to these systematic losses within cooling equipment due to inherent building microclimates. While there are many ways the study could be refined, the results from this study carry order of magnitude significance since many assumptions are conservative. Because our baseline for the ideal case serves as the reference for the analysis, simplifications that eliminate fluctuations and stochasticity that one would expect to see in energy use data become irrelevant.

A sensitivity analysis shows that our assumptions for the ideal case do not influence energy consumption significantly. For instance, the heat rejection temperature, $T_{\text {hot }}$ for the air conditioner heat exchanger, was held at a constant of $30^{\circ} \mathrm{C}$. During periods of high demand, this may be closer to $35^{\circ} \mathrm{C}$ since ambient conditions in the city would be over $30^{\circ} \mathrm{C}$. In general, we would expect fluctuations across the heat exchanger to be $5^{\circ} \mathrm{C}$ higher or lower. For the UHI case, an increase to $35^{\circ} \mathrm{C}$ changes the impact on energy demand from of $15 \%$ to an increase of $13 \%$ more. The overall energy increase changes from 4600 TJ to 3900 TJ. These are similar numbers, particularly considering the goal of demonstrating how fundamental thermodynamics of building systems are impacted by urban climatic changes. Since the values for electricity increase due to UHI, stack effects, and rooftop effects are all based on an ideal case, this ideal case could be arbitrarily assigned somewhere within a verifiable range, and the final output would not differ greatly as shown in Figure 7. 


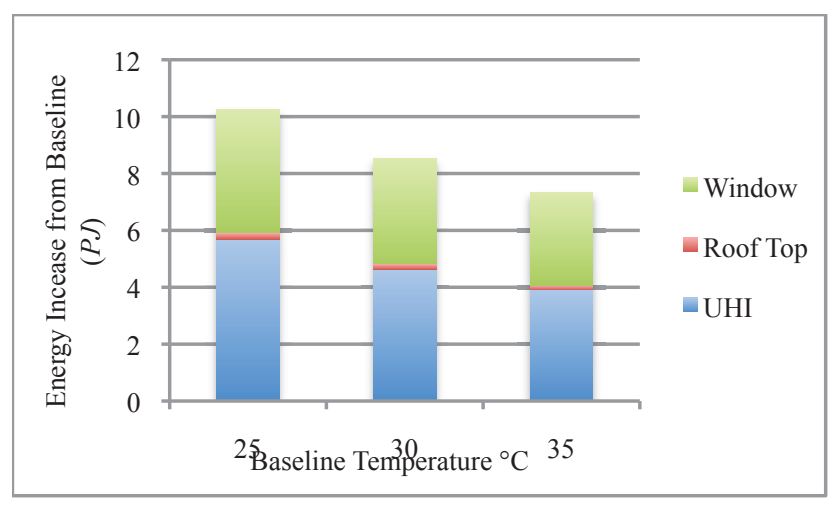

Figure 7: Sensitivity of energy increase in PJ relative to the temperature increase from the idealized baseline temperature for each factor, window unit, roof top unit, and UHI.

Similarly, constant machine efficiencies were chosen for each study. This is an important metric when looking at the absolute COP, however when calculating the increase from a baseline, ideal case, this change is disconnected from efficiency. Again looking at the UHI case, a constant machine efficiency of $50 \%$ and $30{ }^{\circ} \mathrm{C}$ for $T_{\text {hot }}$ gives a COP of 5.7. Because we are calculating a baseline COP and a modified COP as shown in Equation 2, the percent change in primary energy demand is a ratio of these two COPs making the constant machine efficiency cancel out. Therefore the machine efficiency only plays a role in determining our absolute COP estimates.

In summary, isolating the effects from the three criteria outlined in section 4 , and viewing them solely in the reference frame of a smaller building microclimate, demonstrates the importance of these phenomena back at the city scale. For this reason, while the particular input parameters were for NYC, the observations could be translated to other cities.

\section{Conclusion}

This paper investigated the impact of the three factors, UHI, roof top material, and stack effect, on the electricity consumption due to cooling within New York City. The impact of each individual factor on the ambient temperature was investigated first to calculate the change of an air conditioner's COP. The next step was to estimate the number of units influenced by the effect and calculate the total increase in electricity demand from each factor.

The influence of each factor is significant for the total energy budget of the city, between 50-6700 TJ annually, 
roughly up to $1 \%$ of the overall electricity consumption in New York City. The stack effect observed with window air conditioning units, guided by geometry, holds the highest potential and also requires the least impact to change. While the adjustment of surface materials and the mitigation of the UHI requires a lot of financial investment, the stack effect requires only the adjustment of the individual location of each heat exchanger in respect to the other heat exchangers.

The next steps are to quantify further the effect of the stack effect by measuring different location in the city. This provides a solid foundation for further inquiry. To broaden the impact of this investigation, a cost-benefit analysis to determine the payback period can be conducted for individual apartments. A cost benefit analysis would help motivate residents to invest and change the location of their heat exchangers and mitigate the energy budget of the city. Future work on roof top material and air conditioner packaging geometries may elucidate a stronger effect on air temperature than currently reported in literature.

\section{Acknowledgment}

This paper is the extension from the 2015 IBPC conference proceeding, "Urban Cooling Potential: System Losses from Microclimates.” This study was funded in part by the US National Science Foundation's Sustainability Research Network Cooperative Agreement \# 1444758.

\section{References}

[1] Z.-H. Wang, E. Bou-Zeid, and J. A. Smith, “A Spatially-Analytical Scheme for Surface Temperatures and Conductive Heat Fluxes in Urban Canopy Models," Bound.-Layer Meteorol., vol. 138, no. 2, pp. 171-193, Oct. 2010.

[2] T. R. Oke, "Canyon geometry and the nocturnal urban heat island: comparison of scale model and field observations," $J$. Climatol., vol. 1, no. 3, pp. 237-254, 1981.

[3] H. Takebayashi and M. Moriyama, "Surface heat budget on green roof and high reflection roof for mitigation of urban heat island," Build. Environ., vol. 42, no. 8, pp. 2971-2979, Aug. 2007.

[4] M. Santamouris, N. Papanikolaou, I. Livada, I. Koronakis, C. Georgakis, A. Argiriou, and D. N. Assimakopoulos, “On the impact of urban climate on the energy consumption of buildings," Sol. Energy, vol. 70, no. 3, pp. 201-216, 2001.

[5] G. A. Meehl, T. Karl, D. R. Easterling, S. Changnon, R. Pielke, D. Changnon, J. Evans, P. Y. Groisman, T. R. Knutson, K. E. Kunkel, L. O. Mearns, C. Parmesan, R. Pulwarty, T. Root, R. T. Sylves, P. Whetton, and F. Zwiers, "An Introduction to Trends in Extreme Weather and Climate Events: Observations, Socioeconomic Impacts, Terrestrial Ecological Impacts, and Model Projections*," Bull. Am. Meteorol. Soc., vol. 81, no. 3, pp. 413-416, Mar. 2000.

[6] M. Santamouris, A. Synnefa, and T. Karlessi, "Using advanced cool materials in the urban built environment to mitigate heat islands and improve thermal comfort conditions," Sol. Energy, vol. 85, no. 12, pp. 3085-3102, Dec. 2011.

[7] M. Zinzi, "Cool materials and cool roofs: Potentialities in Mediterranean buildings," Adv. Build. Energy Res., vol. 4, no. 1, pp. 201-266, Jan. 2010.

[8] J. Allegrini, V. Dorer, J. Carmeliet. "Influence of the urban microclimate in street canyons on the energy demand for space cooling and heating of buildings," Energy and Buildings, vol. 55, 823-832, 2012. 
[9] S. Gracik, M. Heidarinejad, J. Liu, J. Srebric, "Effect of urban neighborhoods on the performance of building cooling systems," Building and Environment, vol. 90, 15-29, 2015.

[10] R. T. A. Prado and F. L. Ferreira, "Measurement of albedo and analysis of its influence the surface temperature of building roof materials," Energy Build., vol. 37, no. 4, pp. 295-300, Apr. 2005.

[11] F. Yuan and M. E. Bauer, "Comparison of impervious surface area and normalized difference vegetation index as indicators of surface urban heat island effects in Landsat imagery," Remote Sens. Environ., vol. 106, no. 3, pp. 375-386, Feb. 2007.

[12] K. L. Uemoto, N. M. N. Sato, and V. M. John, "Estimating thermal performance of cool colored paints," Energy Build., vol. 42, no. 1, pp. 17-22, Jan. 2010.

[13] C. Y. Jim, "Air-conditioning energy consumption due to green roofs with different building thermal insulation," Appl. Energy, vol. 128, pp. 49-59, Sep. 2014.

[14] F. Bourbia and H. B. Awbi, "Building cluster and shading in urban canyon for hot dry climate: Part 1: Air and surface temperature measurements," Renew. Energy, vol. 29, no. 2, pp. 249-262, Feb. 2004.

[15] N. H. Wong, Y. Chen, C. L. Ong, and A. Sia, "Investigation of thermal benefits of rooftop garden in the tropical environment," Build. Environ., vol. 38, no. 2, pp. 261-270, Feb. 2003.

[16] L. Hoffman, G. Loosvelt, and R. Berghage, "Green Roof Thermal and Stormwater Management Performance: The Gratz Building Case Study, New York City,” NYSERDA, New York City, Pratt Center for Community Development Final Report 09-05, Dec. 2010.

[17] S.-H. Choi, "Effects of stacked condensers in a high-rise apartment building," Energy, pp. 968-981, Jun. 2005.

[18] M. Bruelisauer, F. Meggers, E. Saber, C. Li, and H. Leibundgut, "Stuck in a Stack - Temperature measurements of the microclimate around split type condensing units in a high rise building in Singapore," Energy Build., vol. 71, pp. 28-37, Mar. 2014.

[19] M. Bruelisauer and S. Berthold, Eds., Reclaiming Backlanes. World Scientific Press, 2015.

[20] M. Bruelisauer, F. Meggers, and H. Leibundgut, "Heat Bus System to refurbish a high-rise residential building with semicentralised high-performance chillers," in 6th International Building Physics Conference, IBPC 2015, Torino, Italy, 2015.

[21] I. J. Hall, R. R. Prairie, H. E. Anderson, and E. C. Boes, "Generation of a Typical Meteorological Year," Sandia Labs., Albuquerque, NM (USA), SAND-78-1096C; CONF-780639-1, Jan. 1978.

[22] J. Bryant and A. Moore, "Economic Snapshot: A Summary of New York City's Economy, " in NYCEDC Economic Research \& Analysis, July 2013

[23] C. Kontokosta, "Local Law 84 Energy Benchmarking Data: Report to the New York City Mayor's Office of Long-Term Planning and Sustainability." (2012).

[24] H. Tran, D. Uchihama, S. Ochi, and Y. Yasuoka, "Assessment with satellite data of the urban heat island effects in Asian mega cities," Int. J. Appl. Earth Obs. Geoinformation, vol. 8, no. 1, pp. 34-48, Jan. 2006.

[25] C. Rosenzweig, W. D. Solecki, and R. B. Slosberg, "Mitigating New York City's Heat Island with Urban Forestry, Living Roofs, and Light Surfaces," NYSERDA, New York City, New York City Regional Heat Island Initiative Final Report 0606, Oct. 2006.

[26] B. de Blasio and J. Jiha, “Annual Report on the NYC Property Tax FY 2014,” Office of Tax Policy, Jun. 2014.

[27] D. EIA, Commercial Building Energy Consumption Survey (CBECS). 2012.

[28] D. Westphalen and S. Koszalinski, "Energy Consumption Characteristics of Commercial Building HVAC Systems Volume II: Thermal Distribution, Auxiliary Equipment, and Ventilation," Arthur Little Inc ADLI, vol. 20, pp. 33745-00, 1999.

[29] M. Zuluaga, S. Maxwell, J. Block, and L. Eisenberg, "There are Holes in our Walls," Urban Green Council.

[30] D. EIA, Residential Energy Consumption Survey (RECS). 2008.

[31] M. Georgescu, W. T. L. Chow, Z. H. Wang, A. Brazel, B. Trapido-Lurie, M. Roth, and V. Benson-Lira, "Prioritizing urban sustainability solutions: coordinated approaches must incorporate scale-dependent built environment induced effects," Environ. Res. Lett., vol. 10, no. 6, p. 061001, 2015.

[32] N. Vercauteren, E. Bou-Zeid, H. Huwald, M. B. Parlange, and W. Brutsaert, "Estimation of wet surface evaporation from sensible heat flux measurements," Water Resour. Res., vol. 45, no. 6, p. W06424, Jun. 2009.

[33] E. Teitelbaum, F. Meggers, G. Scherer, P. Ramamurthy, L. Wang, and E. Bou-Zeid, "ECCENTRIC Buildings: Evaporative Cooling in Constructed ENvelopes by Transmission and Retention Inside Casings of Buildings," in 6th International Building Physics Conference, IBPC 2015, Torino, Italy, 2015.

[34] M. Bruelisauer, S. Berthold, G. Aschwanden, I. Belle, E. Ostertag, and F. Meggers, "Reclaiming backlanes - addressing energy efficiency, outdoor comfort and urban space," in Proceedings of the SB13 Singapore, Singapore, 2013.

[35] G. D. Jenerette, S. L. Harlan, W. L. Stefanov, and C. A. Martin, "Ecosystem services and urban heat riskscape moderation: water, green spaces, and social inequality in Phoenix, USA," Ecol. Appl., vol. 21, no. 7, pp. 2637-2651, Oct. 2011.

[36] F. Meggers, G. Aschwanden, E. Teitelbaum, H. Guo, and M. Bruelisauer, "Urban Cooling Potential: System Losses from Microclimates," in 6th International Building Physics Conference, IBPC 2015, Torino, Italy, 2015. 